\title{
Interactions of light and organic matter under contrasting resource simulated environments: the importance of clonal traits in the seagrass Zostera noltii
}

\author{
Irene Olivé · M. Paz García-Sánchez • \\ Fernando G. Brun · Juan J. Vergara • \\ J. Lucas Pérez-Lloréns
}

Published online: 21 April 2009

(C) The Author(s) 2009. This article is published with open access at Springerlink.com

\begin{abstract}
Light reduction in the water column and enhanced organic matter (OM) load into the sediments are two main consequences of eutrophication in marine coastal areas. This study addresses the combined effects of light, OM, and clonal traits in the seagrass Zostera noltii. Large Z. noltii plants were grown in sand with or without the addition of OM and under two light levels (high light and low light). Whereas some complete plant replicates were grown under homogeneous light and/or OM conditions, other replicates were grown under contrasting light and/or OM levels between the apical and the distal parts of the same plant. The three-way factorial design (light, OM load, and apex position) allowed us to determine
\end{abstract}

Guest editors: J. H. Andersen \& D. J. Conley Eutrophication in Coastal Ecosystems: Selected papers from the Second International Symposium on Research and Management of Eutrophication in Coastal Ecosystems, 20-23 June 2006, Nyborg, Denmark

I. Olivé · M. P. García-Sánchez · F. G. Brun ·

J. J. Vergara · J. L. Pérez-Lloréns

Departamento de Biología, Área de Ecología, Facultad de Ciencias del Mar y Ambientales, Universidad de Cádiz, 11510 Puerto Real, Cádiz, Spain

e-mail: irene.olive@uca.es

F. G. Brun $(\square)$

Netherlands Institute of Ecology (NIOO-KNAW),

Centre for Estuarine and Marine Ecology, Korringaweg 7, 4401 NT Yerseke, The Netherlands

e-mail: fernando.brun@uca.es the harmful effect of light reduction and OM enrichment on the growth, photosynthetic performance, and biochemical composition of $Z$. noltii. The addition of $\mathrm{OM}$ to the sediment promoted a decrease, or even an inhibition, in net plant growth regardless of the light level when the whole plants were grown under homogeneous light conditions. However, the results differed when plants were grown under contrasting light and/or OM conditions between apical and distal parts. In this case, the harmful effect of OM load was alleviated when apical parts were grown under high light conditions. OM loads also negatively affected the photosynthetic performance, evaluated as leaf fluorescence. The results indicate the importance of clonal traits in the response of $Z$. noltii growth to light conditions and $\mathrm{OM}$ enrichment.

Keywords Apical dominance - Clonal integration . Growth · Light · Organic matter · Zostera noltii

\section{Introduction}

Seagrass beds, with their high productivity and biodiversity, have significant ecological and economic value (Costanza et al., 1997). In the past decades, the eutrophication observed in many coastal waters associated with an increase in nutrient loadings from wastewater, agricultural runoff, and other sources has been considered as a probable cause of the decline in the distribution of seagrasses in 
temperate coastal environments (Hemminga \& Duarte, 2000).

Two important processes have been linked to eutrophication-driven seagrass declines. First, nutrient enrichment stimulates the massive growth of phytoplankton, epiphytes (micro- and/or macro-), and free-floating opportunistic macroalgae (Valiela et al., 1997), which results in reduced light levels to the seagrasses beneath. Because the compensation irradiance for seagrass growth is higher than that for most ephemeral macroalgae (Enríquez et al., 1996), such light reduction may result in a negative seagrass growth (Longstaff et al., 1999; Brun et al., 2003b).

Second, there is an increased loading of sediments with organic matter (OM) as blooming algae die off (Borum \& Sand-Jensen, 1996), increasing the respiration of the benthic microbial community (Jørgensen \& Richardson, 1997; Holmer, 1999). Since the diffusion of oxygen from the overlying water into the sediment pore water is low (Kemp et al., 1992), and the basipetal translocation (from leaves to below-ground parts) of sucrose and oxygen and further release to the rhizosphere are reduced (as a consequence of lower light availability) (Smith et al., 1984; Zimmerman et al., 1996), this may generate a reduction in the redox potential of the sediments leading to anoxia. Such conditions are harmful to seagrasses not only because of the decrease of oxygen and sucrose transfer to the below-ground parts, but also because the occurrence of sulfide compounds in the surroundings of the rhizosphere may result in toxicity (Hemminga, 1998; Holmer \& Bondgaard, 2001).

Besides the effects of eutrophication on seagrass meadows described above, seagrass growth promotes the emergence of biotic and abiotic gradients between seagrass beds and adjacent bare areas (Vichkovitten \& Holmer, 2005) and even within the seagrass meadow itself (Brun et al., 2003a). For example, the 'edge effect', where runner shoots (apical shoots) escape from the meadow, implies a reduction in shoot density and a concomitant increase in light levels at the edge (Duarte \& Sand-Jensen, 1990; Brun et al., 2003a; Enríquez \& Pantoja-Reyes, 2005; Sintes et al., 2005). Nutrient concentrations in the pore water are lower at the meadow edges because plant biomass has been positively correlated with $\mathrm{OM}$ pools and sedimentation rates (Holmer \& Nielsen, 1997; Barrón et al., 2004). Therefore, light levels are higher at the meadow periphery whereas nutrient concentrations (mostly in sediment pore water) and $\mathrm{OM}$ are higher in the central parts of the meadow (Pedersen et al., 1997) resulting in a divergent resource allocation within the same clone.

Elucidation of the relative importance of light and OM loading on seagrass viability requires an experimental approach (Hemminga \& Duarte, 2000). Most studies have been carried out looking at the effect of light reduction on seagrass physiology, growth, or meadow attributes (see review table in Brun et al., 2006). In comparison, few studies have been devoted to investigating the effect of OM loads (Terrados et al., 1999; Cancemi et al., 2003), while the combined effects of light and $\mathrm{OM}$ on seagrass growth, survival and photosynthetic activity have rarely been reported (Short et al., 1995; Holmer \& Laursen, 2002; Holmer et al., 2005). In addition, the role of clonality in seagrass responses to light and/or OM loads has not yet been fully studied.

Clonality implies that the rhizome network, in addition to the anchorage and storage roles, is a sort of 'pipe' that physically and physiologically interconnects shoots (throughout 'clonal integration') within a single plant (Cline, 1997) and is governed by apical shoots [throughout 'apical dominance' (Terrados et al., 1997)]. Plants could benefit from the emergence of abiotic gradients within the meadow if clonal traits work at long distances, as was suggested by Marbà et al. (2002). Therefore, this would result in enhanced growth and meadow spreading because nutrients and photosynthates would be re-allocated within the plant mainly toward the apical shoots (Tomasko \& Dawes, 1989; Marbà et al., 2002). Accordingly, clonality arises as an important issue for a better understanding of the effects of external forcing in seagrass ecology.

The aim of this study was to evaluate the interaction between light and $\mathrm{OM}$ enrichment on growth, photosynthesis (fluorescence), and elemental composition of the seagrass Zostera noltii taking into account its clonal nature.

\section{Materials and methods}

Sampling site

Specimens of Zostera noltii were collected from an intertidal sandy meadow at Santibañez (Cadiz Bay 
Natural Park, $\left.36^{\circ} 32^{\prime} \mathrm{N}, 6^{\circ} 15^{\prime} \mathrm{W}\right)$ in spring 2004 during the onset of its maximum growth phase (Brun et al., 2003a; Peralta et al., 2005). Plants were gathered carefully to keep below-ground parts intact and transported to the laboratory in an ice-chest. Before any experimental manipulation, plants were gently rinsed in seawater and visible epiphytes were removed by scraping carefully with paper. A total of 72 plants, with 5-6 internodes and one shoot per node, were selected and acclimated to the laboratory conditions in a clear aquarium during $24-48 \mathrm{~h}$. All specimens were measured (number of internodes, internode lengths, total rhizome length, number of shoots, and leaf length), weighed (fresh weight, FW), and the rhizome axis was tagged at both ends (i.e., apical and distal positions).

\section{Experimental design}

The effects of light, OM load, and 'plant portion' (i.e., apical versus distal plant parts) on growth, photosynthesis, and tissue elemental composition of Z. noltii were assessed using a three-way factorial design [2 light levels (high versus low) $\times 2$ OM treatments (non-enriched versus enriched) $\times 2$ 'plant portions' (apical part versus distal part)] in a mesocosm experiment.

Plants were transplanted into the aquaria according to the designed treatment of light [high light (HL) or

Fig. 1 Experimental design of the treatments in the aquaria. White arrows represent high light (HL), dark arrows represent low light (LL). (-) represents sediment without OM and (+) represents sediment with OM. The head of the arrows indicates the apical part of the plant. Each arrow indicates one plant. All aquaria were duplicated low light (LL)], OM [without OM (-) or with OM $(+)$ ] and position of the apical shoots. One set of plants was grown under 'homogeneous conditions'; that is, the entire plant was subjected to the same light and OM treatments (aquaria 1-4, Fig. 1). The remaining set of plants was grown under 'heterogeneous conditions'; that is, the apical half and distal half parts of the plant were subjected to different combinations of light and/or OM loads (aquaria 5-8, Fig. 1). To achieve this objective, aquaria were split into two halves (before adding the sand) using a holed transparent-perspex septum to allow a tight passage of the rhizome axis in a way that apical and distal plant parts could undergo contrasting experimental conditions. Three plants per aquarium $(n=3)$ were set in 'homogeneous' aquaria (1-4, Fig. 1) and six plants per aquarium ( $n=3$ apical orientation and $n=3$ distal orientation) were set in 'heterogeneous' aquaria (5-8, Fig. 1). All the treatments were run in duplicated aquaria.

Plants were grown for 21 days in an incubation chamber (D-1400-3BL, ASL) at $18^{\circ} \mathrm{C}$. This time span is long enough to detect any treatment-driven changes in the growth dynamic parameters of Zostera noltii (Brun et al., 2002; Peralta et al., 2002). Whole plants (in 'homogeneous conditions') or plant halves (in 'heterogeneous conditions') were exposed to either saturating light (HL, $120 \mu \mathrm{mol}$ quanta $\mathrm{m}^{-2} \mathrm{~s}^{-1}$ ) or limiting light (LL, $35 \mu \mathrm{mol}$ quanta $\mathrm{m}^{-2} \mathrm{~s}^{-1}$ )
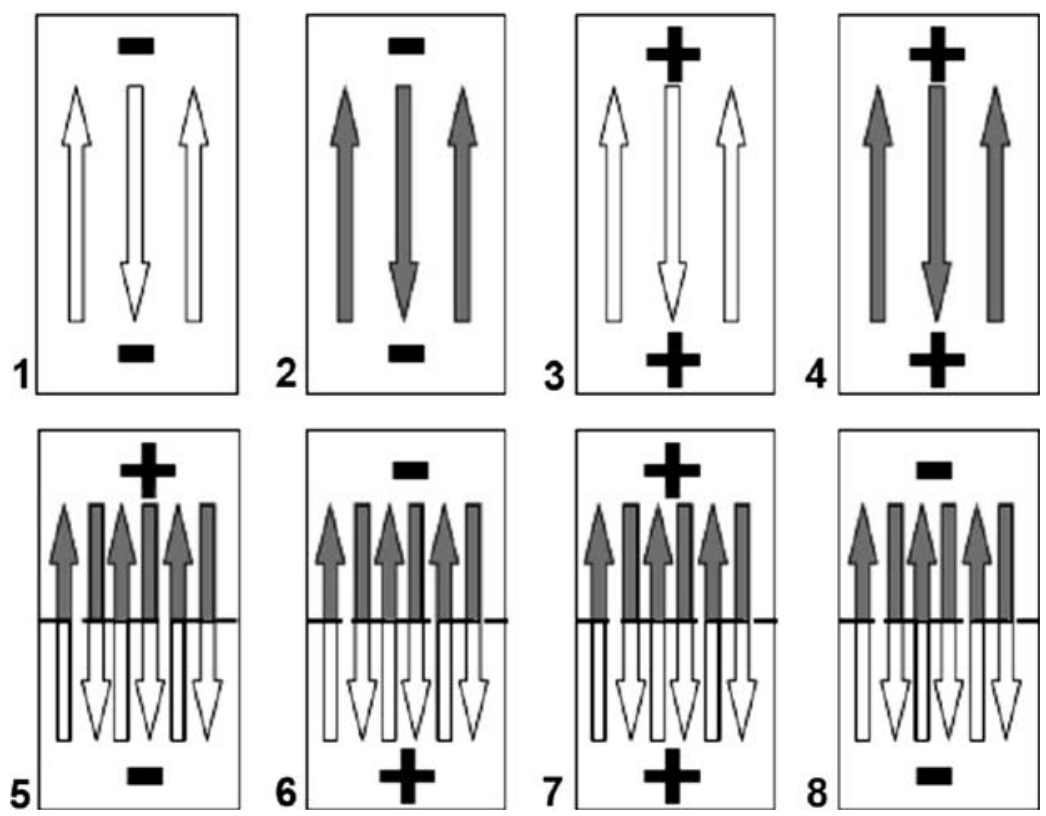
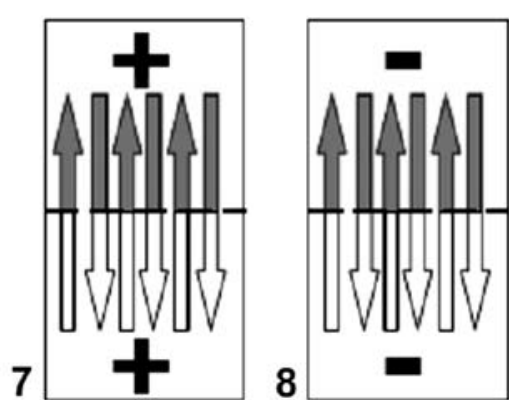
depending on the experimental design. A 13:11 h light:dark photoperiod was established. Photon flux was measured with a LI 193 SA (LiCor) quantum meter mounted with a $4 \pi$ PAR (400-700 nm) sensor. Light was supplied with fluorescent tubes (Philips TLD 18w/ 865). The limiting light level was achieved using neutral density filters to wrap the aquaria. Seawater in the aquaria was renewed once a week. To minimize any variation in light levels among the aquaria undergoing the same light conditions, they were randomly relocated on the shelves of the chamber after each water change. Water in the aquaria was homogenized with an air-pumping system. Redox potential was measured weekly (in each renovation of water) with redox potential electrodes (Redox combination electrode, SebTix ORP, WTW).

Sandy sediment was gently acid-washed and rinsed with tap water to reduce the amount of OM. Seawater was also filtered with cellulose paper. For the enriched OM treatments $[(+) \mathrm{OM}]$, acid-washed sediment was supplemented with a mixture of ground Ulva sp. (4.7 $\mathrm{g} \mathrm{DW}^{-1}$ dry sediment) and sucrose (18 $\mathrm{g} \mathrm{l}^{-1}$ dry sediment).

\section{Plant growth}

After 21 days of culture, plants were collected, measured, split into apical and distal portions (and further into above- and below-ground biomass), and weighed to determine the following dynamic growth parameters according to Peralta et al. (2002): plant net growth rate (GR, mg FW plant $\left.{ }^{-1} \mathrm{~d}^{-1}\right)$, internode elongation rate (IER, $\mathrm{cm}_{\text {plant }}{ }^{-1} \mathrm{~d}^{-1}$ ), and internode appearance rate (IAR, no. of internodes plant ${ }^{-1} \mathrm{~d}^{-1}$ ). The ratio of above-ground:below-ground biomass (AG:BG) was also calculated on a fresh-weight basis.

\section{Photosynthetic performance}

Before weighing, photosynthetic characteristics of the leaves were assessed by determining the maximum photochemical efficiency of photosystem II $\left(F_{\mathrm{v}} /\right.$ $F_{\mathrm{m}}$ ) using chlorophyll- $a$ fluorescence (for details on this technique, see Krause \& Weis, 1991). The measurements were made with a PAM-2000 (Walz Effeltrich, Germany). To reduce any within-shoot variability in $F_{\mathrm{v}} / F_{\mathrm{m}}$, fluorescence was measured in the middle part of the second innermost leaf of randomly selected shoots along the plant. In plants under heterogeneous conditions (aquaria 5-8), measurements were conducted in both halves of the aquaria after selecting shoots randomly in each half. A leaf clip (DLC, Walz) connected with fiber optics to the fluorometer was mounted in the middle part of the leaf. A 5-s weak far-red pulse was applied to oxidize the electron transport chain (Hanelt, 1998), after which the shutter of the clips was closed. After 5 min of dark acclimation, the ground fluorescence $\left(F_{0}\right)$ was estimated, followed by a saturating pulse to measure maximal fluorescence $\left(F_{\mathrm{m}}\right)$, allowing calculation of the variable fluorescence $\left(F_{\mathrm{v}}=F_{\mathrm{m}}-F_{0}\right)$ and the maximum photochemical efficiency $\left(F_{\mathrm{v}} / F_{\mathrm{m}}\right)$.

Elemental composition

Above-ground parts (shoots) and below-ground parts (rhizomes + roots) from apical and distal portions of the plants were oven-dried $\left(60^{\circ} \mathrm{C}\right)$ until constant weight to determine the dry weight of each fraction. Sub-samples of all fractions were powdered and stored for nutrient content analysis. Tissue carbon (C) and nitrogen $(\mathrm{N})$ were determined using a PerkinElmer $240 \mathrm{CNH}$ elemental analyzer.

\section{Statistical analysis}

The effects of light availability, OM, and plant portion on the growth, photosynthesis and biochemical composition of $Z$. noltii were determined using a hierarchical (nested) analysis of variance (ANOVA). The levels of variability were the aquaria on each treatment $(n=2)$ and the plants sampled within each aquarium ( $n=3$ aquaria $1-4 ; n=6$ (3 apical +3 distal) aquaria 5-8). Normality of the data and homogeneity of variances were tested (Zar, 1984). Multiple post-hoc comparisons between means were assessed by the Unequal N HSD procedure. For nonparametric data, the Kruskal-Wallis test was used. Results are expressed as mean $\pm \mathrm{SE}$.

\section{Results}

Abiotic variables

Initial light levels in the aquaria were 120 and $35 \mu \mathrm{mol}$ quanta $\mathrm{m}^{-2} \mathrm{~s}^{-1}$ (HL and LL, respectively). In the HL treatments, there was a slight decrease of 


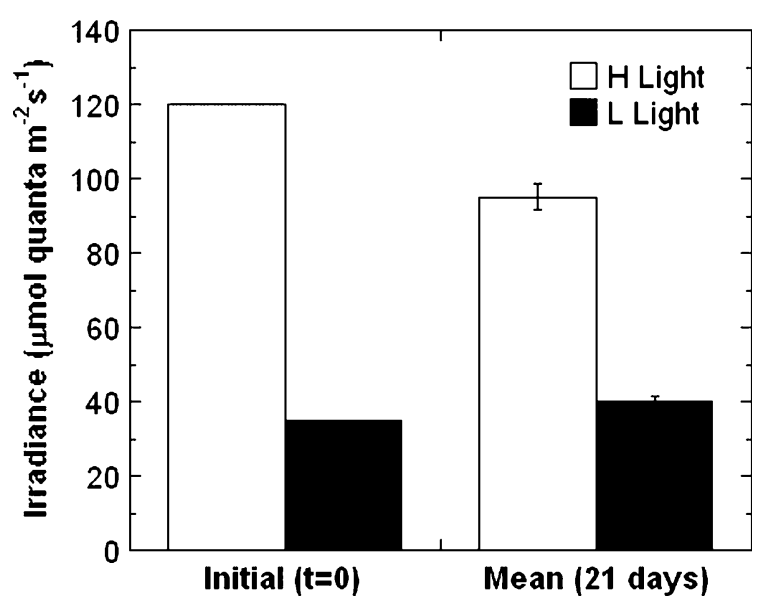

Fig. 2 Irradiance levels at the bottom of the aquaria at the beginning of the experiment [initial $(t=0)]$ and the mean value during the 21 days of culture [mean (21 days)] for aquaria at high light (white column) and low light (dark column) conditions

irradiance during the experiment owing to an increase in turbidity, probably caused by phytoplankton and bacterial growth, even though the seawater was renewed weekly (Fig. 2). Thus, the mean irradiance for all the aquaria during the experiments was $95 \pm 3.6 \mu \mathrm{mol}$ quanta $\mathrm{m}^{-2} \mathrm{~s}^{-1}$ (HL) and $40 \pm$ $1.2 \mu \mathrm{mol}$ quanta $\mathrm{m}^{-2} \mathrm{~s}^{-1}$ (LL) (Fig. 2) and differences in light dose remained significant during the experiment $(P<0.001)$.

The OM content of the sediments at the beginning of the experiments was $2.20 \pm 0.13 \%$ DW for OMenriched sediments $[(+) \mathrm{OM}]$ and $0.55 \pm 0.04 \% \mathrm{DW}$ for non-OM-enriched sediments [(-) OM] (Fig. 3). At the end of the incubations, the percentage of $\mathrm{OM}$ in the sediment decreased significantly to half of initial content in the $(+)$ OM sediments $(0.95 \pm$ $0.03 \% \mathrm{DW})$, whereas the percentage increased slightly in the (-) OM sediments $(0.80 \pm 0.03 \%$ DW) (Fig. 3). However, significant differences in the sediment OM content between (+) OM and (-) OM treatments persisted up to the end of the experiment $(P<0.05)$. Redox potential in the sediment was unaffected by the light regime but depended largely on the OM content (data not shown). The lowest redox potential values were recorded at the end of the experiment in (+) OM sediments $(-312 \pm 8 \mathrm{mV}$, $n=12$ ), whereas 4 -fold higher values were recorded in (-) OM sediments $(-75 \pm 38 \mathrm{mV}, n=12)$.

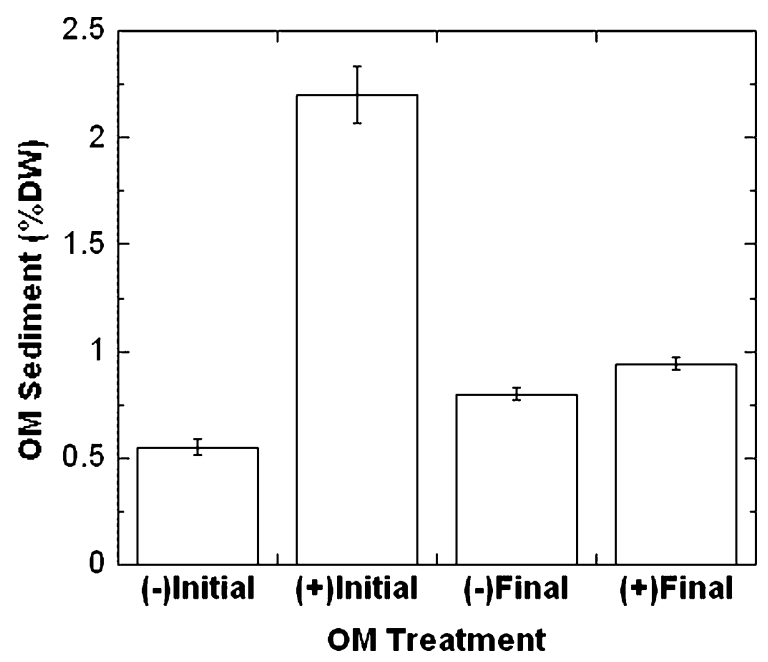

Fig. 3 Organic matter content (\% DW) in the sediment without $(-)$ and with (+) $\mathrm{OM}$ at the beginning (initial) and at the end (final) of the experiment

Plant dynamic parameters

Both light and OM significantly affected all plant dynamic parameters measured at the end of the experiment (Table 1). When the whole plants were grown under 'homogeneous conditions' (i.e., the entire plant was subjected to the same light and OM treatments; aquaria 1-4, Fig. 4), a significant decrease in net growth rates (GR), net internode elongation rates (IER), and net internode appearance rates (IAR) was observed under $(+) \mathrm{OM}$ regardless of the light regime (Fig. $4 \mathrm{~A}-\mathrm{C}$; aquaria 3 and 4 compared to 1 and 2). However, the results differed when plants were grown under contrasting light between apical and distal parts (Fig. 4, aquaria 7 and 8). Positive IERs were recorded in plants from (-) OM treatments (aquarium 8) regardless of the light regime, while IERs in plants from $(+) \mathrm{OM}$ treatments (aquarium 7) were lower and influenced by the light regime (Fig. 4B; aquaria 7 and 8).

Plants maintained under heterogeneous light and/ or OM conditions showed positive IARs and IERs (but negative GRs) when apical parts were under HL (Fig. 4A-C aquaria 5 and 6), regardless of the $\mathrm{OM}$ conditions. However, lower or negative rates were recorded when the apices were under LL (Fig. 4A-C aquaria 5 and 6).

It should be noted that net GR represents a net biomass balance, while IER and IAR denote the 
Fig. 4 A Growth rates on a fresh-weight basis, GR; B internode elongation rates, IER; $\mathbf{C}$ internode appearance rates, IAR. White columns indicate plants grown at high light (HL) and homogeneous conditions, dark columns indicate plants grown at low light (LL) and homogeneous conditions, soft gray columns indicate plants where apical parts were in HL and distal parts under LL conditions, hatched columns indicate plants where apical parts were in LL and distal parts in HL. (-) means plants without $\mathrm{OM},(+)$ means plants with $\mathrm{OM},(+-)$ means plants where apical parts were grown with $\mathrm{OM}$ and distal parts were without $\mathrm{OM},(-+)$ indicates plants where apical parts were grown without $\mathrm{OM}$ and distal parts were with $\mathrm{OM}$. The numbers on the $x$-axis indicate the number of the aquarium in which the plants were potted. The head of the arrows on the top of the graph indicates the apical part of the plants

actual, integrated growth of the below-ground system of the plants during the experiment. Therefore, net positive IER and IAR can be accompanied by net biomass losses. In this sense, plants grown under homogeneous conditions without OM, regardless of light level (aquaria 1 and 2), presented significant higher GRs than those from the rest of the treatments (homogeneous and heterogeneous) (Fig. 4A, Table 1). This result could indicate that plants from aquaria 1 and 2 were still actively growing at the end of the experiment. Thus, while OM plays an important role in Zostera noltii grown under homogeneous conditions, light becomes the main driving force under heterogeneous conditions. Positive IERs and IARs were mainly recorded in plants where apical portions grew under HL, regardless of the OM treatments.

Above-ground:below-ground fresh biomass ratios (AG:BG) at the end of the experiment showed interesting trends among treatments. On one hand, the AG:BG values for complete plants $(0.3 \pm 0.02)$ (aquaria 1-4) were higher than those for distal portions $(0.1 \pm 0.01)$ but lower than those obtained for apical portions $(0.4 \pm 0.03)$ of split plants. Significant differences were found between complete plants and distal portions $(P<0.005)$ and between apical and distal portions of the split plants $(P<0.0001)$, but no significant differences were detected between complete plants and apical portions. On the other hand, the lowest AG:BG ratios were recorded in plants under LL and (+) OM conditions (data not shown).

Photosynthetic performance (fluorescence)

Maximum photochemical efficiency $\left(F_{\mathrm{v}} / F_{\mathrm{m}}\right)$ was significantly affected by the addition of OM (Fig. 5, Table 1). Thus, shoots grown under (-) OM

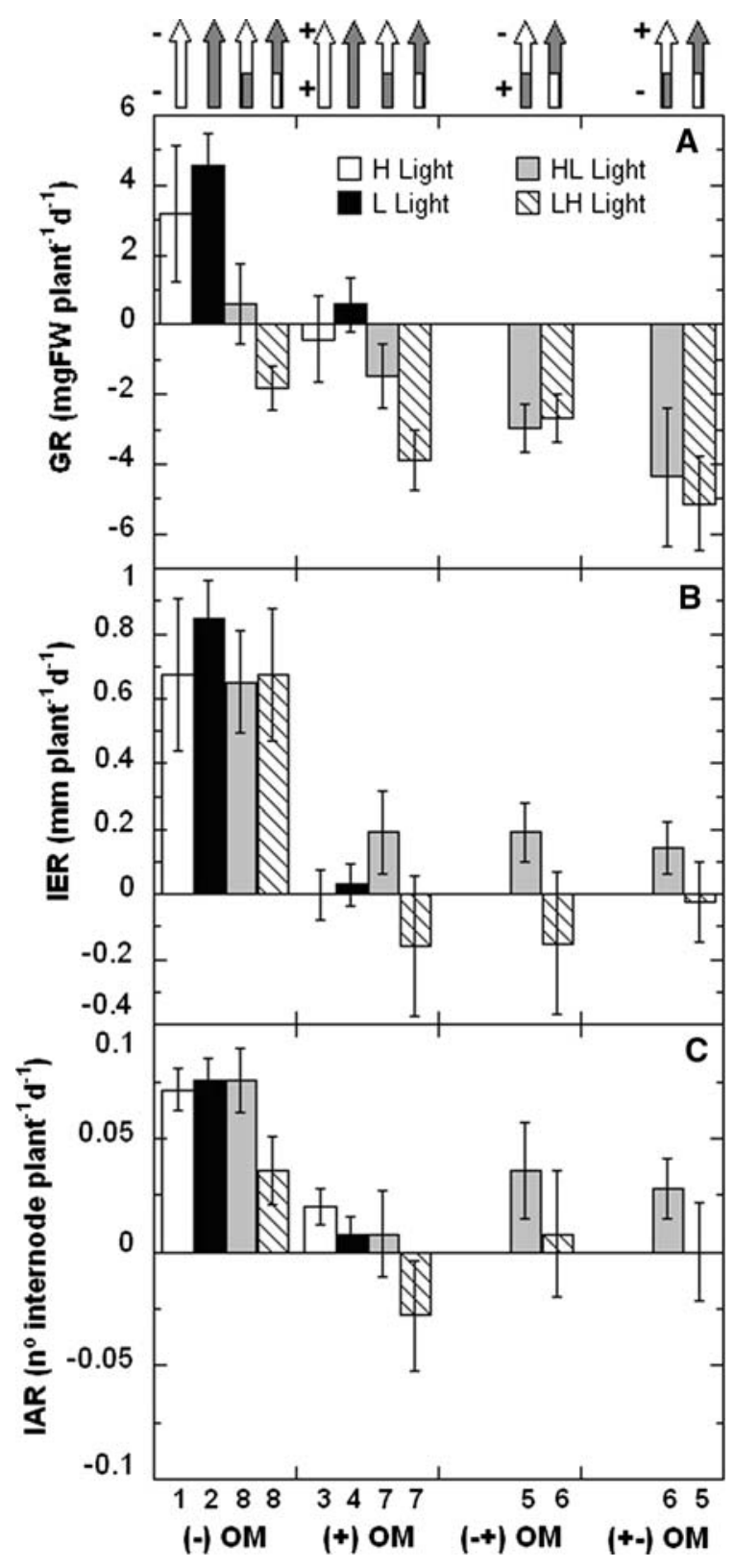

presented higher $F_{\mathrm{v}} / F_{\mathrm{m}}$ values (ca. 0.7) than shoots grown under (+) OM (ca. 0.4) at the end of the experiment, indicating a sub-optimal status of the photosynthetic apparatus in (+) OM plants. Interestingly, the addition of $\mathrm{OM}$ had a greater effect (decrease in $F_{\mathrm{v}} / F_{\mathrm{m}}$ ) in shoots grown in heterogeneous conditions $[( \pm)$ OM treatments] than in shoots from plants grown entirely in $\mathrm{OM}[(+) \mathrm{OM}$ treatment] (Fig. 5). $F_{\mathrm{v}} / F_{\mathrm{m}}$ values were not significantly affected by light growing conditions (Table 1). 
Table 1 Zostera noltii

Statistical results of the ANOVA and the nested ANOVA analyses examining the effects of the light reduction, OM supply, and apical versus distal part of the plant in growth rates (GR, IER, and IAR), fluorescence measurements $\left(F_{\mathrm{v}} / F_{\mathrm{m}}\right)$, and $\mathrm{C}, \mathrm{N}$ content. When data were nonparametric, a KruskalWallis test was applied $d f$ degrees of freedom, $F$ test value

$P$-value where $* P<0.05$, ** $P<0.001$, and n.s. no significant differences

\begin{tabular}{|c|c|c|c|}
\hline Variable (factors) & Statistical text & df treatments/df error & $F(P)$ \\
\hline GR & Nested ANOVA & & \\
\hline Light & & $3 / 60$ & $15.17 *$ \\
\hline OM (Light) & & $8 / 60$ & $3.06 *$ \\
\hline IER & Nested ANOVA & & \\
\hline Light & & $3 / 60$ & $2.87 *$ \\
\hline OM (Light) & & $8 / 60$ & $6.40 *$ \\
\hline IAR & Nested ANOVA & & \\
\hline Light & & $3 / 60$ & $3.62 *$ \\
\hline OM (Light) & & $8 / 60$ & $3.03 *$ \\
\hline Fluorescence $\left(F_{\mathrm{v}} / F_{\mathrm{m}}\right)$ & ANOVA & & \\
\hline $\mathrm{OM}$ & & $3 / 42$ & $6.13 *$ \\
\hline Fluorescence $\left(F_{\mathrm{v}} / F_{\mathrm{m}}\right)$ & ANOVA & & \\
\hline Light & & $3 / 42$ & 0.48 (n.s.) \\
\hline$\% \mathrm{C}$ & ANOVA & & \\
\hline Above- versus below-biomass & & $1 / 77$ & $89.34 *$ \\
\hline$\% \mathrm{~N}$ & ANOVA & & \\
\hline Above- versus below-biomass & & $1 / 77$ & $130.83 *$ \\
\hline$\%$ C Shoot & Nested ANOVA & & \\
\hline Light & & $3 / 19$ & 1.2 (n.s.) \\
\hline OM (Light) & & $8 / 19$ & 1.88 (n.s.) \\
\hline Apical-distal (Light-OM) & & $8 / 19$ & 2.23 (n.s.) \\
\hline \%C Rhizome & Nested ANOVA & & \\
\hline Light & & $3 / 19$ & 0.05 (n.s.) \\
\hline OM (Light) & & $8 / 19$ & 1.97 (n.s.) \\
\hline Apical-distal (Light-OM) & & $8 / 19$ & $5.58 *$ \\
\hline$\%$ N Shoot & Nested ANOVA & & \\
\hline Light & & $3 / 19$ & 0.10 (n.s.) \\
\hline OM (Light) & & $8 / 19$ & $6.78^{*}$ \\
\hline Apical-distal (Light-OM) & & $8 / 19$ & $5.32 *$ \\
\hline$\% \mathrm{~N}$ Rhizome & Kruskal-Wallis & & \\
\hline Light & & 3 & 0.07 (n.s.) \\
\hline $\mathrm{OM}$ & & 3 & 2.98 (n.s.) \\
\hline Apical-distal & & 2 & $21.93 * *$ \\
\hline
\end{tabular}

$\mathrm{C}, 3.0 \% \mathrm{~N}$ in shoots; $24 \% \mathrm{C}, 1.6 \% \mathrm{~N}$ in belowground tissues) than distal parts $(27 \% \mathrm{C}, 2.4 \% \mathrm{~N}$ in shoots; $20 \% \mathrm{C}, 0.9 \% \mathrm{~N}$ in below-ground tissues) (Fig. 6; statistics in Table 1).

\section{Discussion}

The three-way factorial design carried out in this study with light, OM enrichment, and relative plant position allowed the authors a better understanding of the interactions among these three factors and their 


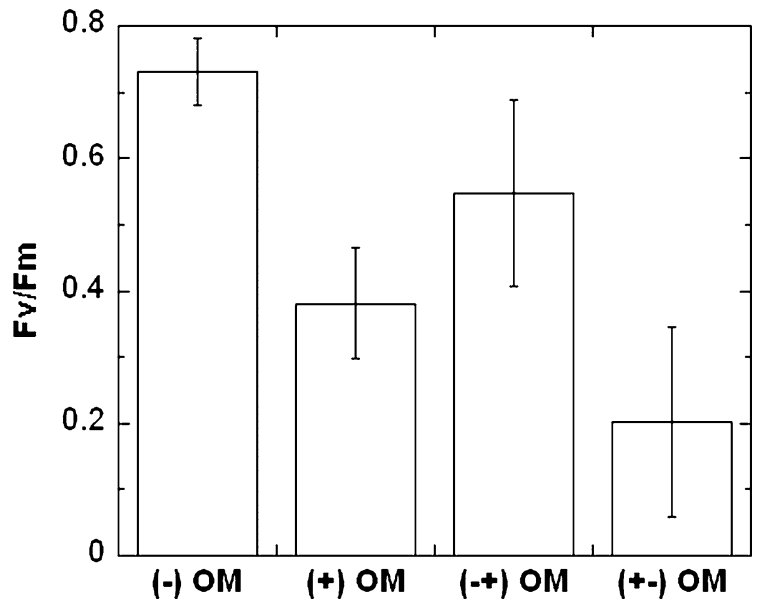

Fig. 5 Maximum photochemical efficiency $\left(F_{\mathrm{v}} / F_{\mathrm{m}}\right)$ of shoots grown under different $\mathrm{OM}$ conditions in $Z$. noltii plants. (-) and $(+) \mathrm{OM}$ indicates plants under homogeneous conditions of $\mathrm{OM}$ (without and with OM, respectively); $(-+)$ and $(+-) \mathrm{OM}$ indicates plants under heterogeneous OM conditions $[(-+)$ means without $\mathrm{OM}$ in apical-with $\mathrm{OM}$ in distal parts and $(+-)$ means with $\mathrm{OM}$ in apical-without $\mathrm{OM}$ in distal parts]

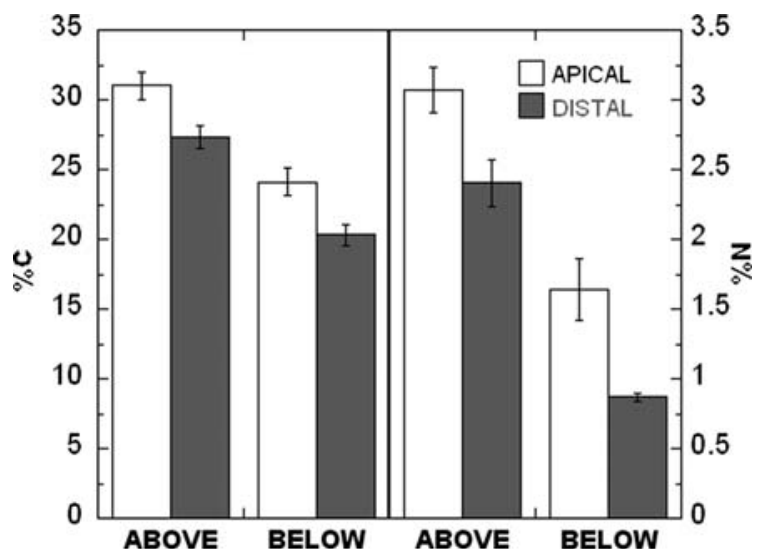

Fig. 6 Carbon and nitrogen content (\% DW) in both aboveground and below-ground tissues of $Z$. noltii. White columns indicate apical portions of the plant and gray columns indicate distal portions

relative importance at the whole-plant level response because the experimental conditions resembled the different situations that could be found in the field.

The clonal nature of seagrass involves the concepts of apical dominance and clonal integration. On one hand, apical dominance denotes the governing influence of the plant apex on the growth and orientation of lateral organs (Woolley \& Wareing,
1972; reviewed by Phillips, 1975). On the other hand, clonal integration allows plants a free-sharing of resources among integrated, connected seagrass modules (Libés \& Boudouresque, 1987; Tomasko \& Dawes, 1989; Marbà et al., 2002).

Plant growth estimators and photosynthesis were affected by OM enrichment, as previously described in other seagrass species (Terrados et al., 1999; Holmer \& Laursen, 2002; Holmer et al., 2005). Light limitation also reduced GR when apices of $Z$. noltii grew under LL, in agreement with previous findings for this species (Peralta et al., 2002; Brun et al., 2003b). However, the novelty of the present approach is the finding that the whole-plant response to both stressors (assayed either alone or together) is modulated by, and largely dependent on, the relative exposure of the plant apex to different conditions and by the existence of contrasting resource environments affecting the same plant. The capacity of these plants to cope with environmental constraints as well as to enhance their potential for colonization would be increased through clonal integration. Accordingly, stressed shoots could be supported by resources provided by modules growing in more favorable conditions, as reported for Thalassia testudinum (Tomasko \& Dawes, 1989). Consequently, such inter-shoot allocation and sharing of resources would reduce the total availability of plant resources and subsequently would reduce the whole plant growth under heterogeneous conditions in contrast to those grown under homogeneous conditions, as recorded in the present study. Therefore, the results presented here show the key role that both clonal traits play in the elucidation of the whole-plant response to single or multiple stressors. Since apical dominance and clonal integration have been suggested to be species-specific, and environmental heterogeneity may occur at several spatial and temporal scales, the evaluation of competition and fitness of a given species living in a particular environment should account for clonal traits and abiotic gradients in order to explain and/or predict the final outcome.

Photosynthesis is the main pathway used by primary producers to acquire energy and organic carbon with a parallel production of molecular oxygen. Since most seagrasses usually inhabit hypoxic to anoxic sediments (Terrados et al., 1999), their survival depends largely on oxygen and resource translocation from shoots to below-ground tissues (Hemminga, 1998). Light reduction diminishes photosynthesis and, 
thus, carbon assimilation and oxygen production (Hemminga, 1998). Decreases in growth rate (GR) and photosynthetic ability (measured as $F_{\mathrm{v}} / F_{\mathrm{m}}$ ) and the presence of necrotic tissues (personal observation) were recorded under $\mathrm{OM}(+)$ treatments. This indicates the harmful effect of the OM, probably mediated by high sulfide concentrations in the rhizosphere (Eh ca. $-300 \mathrm{mV}$ ). It would be expected that the greatest sulfide intrusions occurred in (+) OM treatments under LL, as found by Holmer \& Laursen (2002) and Holmer et al. (2005). Those authors recorded a significant reduction in shoot density, leaf GR, and higher sulfide intrusion rates in plants inhabiting OMenriched sediments under experimental shading. However, our results showed that OM loads caused harmful effects on growth and photosynthesis in complete plants regardless of the light level, both when light and OM were assayed alone or together. The plant damage observed under (+) OM occurred even at HL where it would be expected that light was high enough to drive the allocation of photosynthates and oxygen down to the rhizosphere, thus avoiding anoxia. Nevertheless, the plant response did change when the relative position of $Z$. noltii apices was considered, and contrasting levels of light and/or OM were established along the plant. Synergistic effects of light and OM on plant GR and photosynthesis were recorded (Figs. 4 and 5), revealing the apices as the 'leading' plant parts and more affected by light deprivation than by OM load. In seagrasses, the newly incorporated resources are preferentially allocated into the plant apex (Marbà et al., 2002). Accordingly, the higher AG:BG fresh biomass ratios obtained in apical parts compared to distal parts could suggest that the energetic requirements, including the formation of new photosynthetic tissues, would be higher in apices.

\section{Conclusion}

In conclusion, OM load and light levels significantly affected the growth and photosynthesis of Zostera noltii plants. The full-factorial design applied accounted for the heterogeneity in abiotic conditions recorded in natural meadows. This experimental setup showed that apical dominance and clonal integration modulated the whole-plant response and indicated the importance of both clonal traits in the plant response to the environmental factors assayed.
Acknowledgments This study was supported by the project CTM2005-00395/MAR of the Spanish National Program in Marine Science and Technology from the Ministerio Español de Educación y Ciencia. I. Olivé and M. P. García-Sánchez hold a grant from the Ministerio Español de Educación y Ciencia. F. G. Brun is supported by an individual Marie Curie fellowship (MEIF-CT-2005-515071) and by a European Reintegration Grant (MERG-CT-2007-205675). This is the NIOO publication number 4380.

Open Access This article is distributed under the terms of the Creative Commons Attribution Noncommercial License which permits any noncommercial use, distribution, and reproduction in any medium, provided the original author(s) and source are credited.

\section{References}

Barrón, C., N. Marbà, J. Terrados, H. Kennedy \& C. M. Duarte, 2004. Community metabolism and carbon budget along a gradient of seagrass (Cymodocea nodosa) colonization. Limnology and Oceanography 49: 1642-1651.

Borum, J. \& K. Sand-Jensen, 1996. Is total primary production in shallow coastal marine waters stimulated by nitrogen loading? Oikos 76: 406-410.

Brun, F. G., I. Hernández, J. J. Vergara, G. Peralta \& J. L. Pérez-Lloréns, 2002. Assessing the toxicity of ammonium pulses to the survival and growth of Zostera noltii. Marine Ecology Progress Series 225: 177-187.

Brun, F. G., J. L. Pérez-Lloréns, I. Hernández \& J. J. Vergara, 2003a. Patch distribution and within-patch dynamics of the seagrass Zostera noltii Hornem. in Los Toruños saltmarsh, Cádiz Bay, Natural Park, Spain. Botanica Marina 46: 513-524.

Brun, F. G., J. J. Vergara, G. Navarro, I. Hernández \& J. L. PérezLloréns, 2003b. Effect of shading by Ulva rigida canopies on growth and carbon balance of the seagrass Zostera noltii. Marine Ecology Progress Series 265: 85-96.

Brun, F. G., J. J. Vergara, G. Peralta, M. P. García-Sánchez, I. Hernández \& J. L. Pérez-Lloréns, 2006. Clonal building, simple growth rules and phylloclimate as key steps to develop functional-structural seagrass models. Marine Ecology Progress Series 323: 133-148.

Cancemi, G., G. De Falco \& G. Pergent, 2003. Effects of organic matter input from a fish farming facility on a Posidonia oceanica meadow. Estuarine, Coastal and Shelf Science 56: 961-968.

Cline, M. G., 1997. Concepts and terminology of apical dominance. American Journal of Botany 84: 1064-1069.

Costanza, R., R. d'Arge, R. de Groot, S. Farber, M. Grasso, B. Hannon, K. Limburg, S. Naeem, R. V. O’Neill, J. Paruelo, R. G. Raskin, P. Sutton \& M. van der Belt, 1997. The value of the world's ecosystem services and natural capital. Nature 387: 253-260.

Duarte, C. M. \& K. Sand-Jensen, 1990. Seagrass colonization-biomass development and shoot demography in Cymodocea nodosa patches. Marine Ecology Progress Series 67: 97-103. 
Enríquez, S. \& N. I. Pantoja-Reyes, 2005. Form-function analysis of the effect of canopy morphology on leaf selfshading in the seagrass Thalassia testudinum. Oecologia 145: 235-243.

Enríquez, S., C. M. Duarte, K. Sand-Jensen \& S. L. Nielsen, 1996. Broad scale comparison of photosynthetic rates across phototrophic organisms. Oecologia 108: 197-206.

Hanelt, D., 1998. Capability of dynamic photoinhibition in Arctic macroalgae is related to their depth distribution. Marine Biology 131: 361-369.

Hemminga, M. A., 1998. The root/rhizome system of seagrass: an asset and a burden. Journal of Sea Research 39: 183-196.

Hemminga, M. A. \& C. M. Duarte, 2000. Seagrass Ecology. Cambridge University Press, Cambridge.

Holmer, M., 1999. The effect of oxygen depletion on anaerobic organic matter degradation in marine sediments. Estuarine, Coastal Shelf Science 48: 383-390.

Holmer, M. \& E. J. Bondgaard, 2001. Photosynthetic and growth response of eelgrass to low oxygen and high sulfide concentrations during hypoxic events. Aquatic Botany 70: 29-38.

Holmer, M. \& L. Laursen, 2002. Effect of shading of Zostera marina (eelgrass) on sulfur cycling in sediments with contrasting organic matter and sulfide pools. Journal of Experimental Marine Biology and Ecology 270: 25-37.

Holmer, M. \& S. L. Nielsen, 1997. Sediment sulfur dynamics related to biomass-density patterns in Zostera marina (eelgrass) beds. Marine Ecology Progress Series 146: 163-171.

Holmer, M., M. S. Frederiksen \& H. Møllegaard, 2005. Sulfur accumulation in eelgrass (Zostera marina) and effect of sulfur on eelgrass growth. Aquatic Botany 81: 367-379.

Jørgensen, B. B. \& K. Richardson, 1997. Eutrophication in Coastal Marine Ecosystems. American Geochemical Union Press, USA.

Kemp, V. M., P. Sampou, J. Garber, J. Tuttle \& W. R. Boynton, 1992. Seasonal depletion of oxygen from bottom waters of Chesapeake Bay: roles of benthic and planktonic respiration and physical exchange processes. Marine Ecology Progress Series 85: 137-152.

Krause, G. H. \& E. Weis, 1991. Chlorophyll fluorescence and photosynthesis: the basics. Annual Review of Plant Physiology and Plant Molecular Biology 42: 313-349.

Libés, M. \& C. F. Boudouresque, 1987. Uptake and long-distance transport of carbon in the marine phanerogam Posidonia oceanica. Marine Ecology Progress Series 38: 177-186.

Longstaff, B. J., N. R. Loneragan, M. J. O’Donohue \& W. C. Dennison, 1999. Effects of light deprivation on the survival and recovery of the seagrass Halophila ovalis (R.Br.) Hook. Journal of Experimental Marine Biology and Ecology 234: 1-27.

Marbà, N., M. A. Hemminga, M. A. Mateo, C. M. Duarte, Y. E. M. Mass, J. Terrados \& E. Gacia, 2002. Carbon and nitrogen translocation between seagrass ramets. Marine Ecology Progress Series 226: 287-300.

Pedersen, M. F., C. M. Duarte \& J. Cebrian, 1997. Rates of changes in organic matter and nutrient stocks during seagrass Cymodocea nodosa colonization and stand development. Marine Ecology Progress Series 159: 29-36.

Peralta, G., J. L. Pérez-Lloréns, I. Hernández \& J. J. Vergara, 2002. Effects of light availability on growth, architecture and nutrient content of the seagrass Zostera noltii Hornem. Journal of Experimental Marine Biology and Ecology 269: 9-26.

Peralta, G., F. G. Brun, I. Hernández, J. J. Vergara \& J. L. Pérez-Lloréns, 2005. Morphometric variations as acclimation mechanisms in Zostera noltii beds. Estuarine, Coastal and Shelf Science 64: 347-356.

Phillips, I. D. J., 1975. Apical dominance. Annual Review of Plant Physiology and Plant Molecular Biology 26: 342367.

Short, F. T., D. M. Burdick \& J. E. I. Kaldy, 1995. Mesocosm experiments quantify the effects of eutrophication on eelgrass, Zostera marina. Limnology and Oceanography 40: 740-749.

Sintes, T., N. Marba, C. M. Duarte \& G. A. Kendrick, 2005. Nonlinear processes in seagrass colonisation explained by simple clonal growth rules. Oikos 108: 165-175.

Smith, R. D., W. C. Dennison \& R. S. Alberte, 1984. Role of seagrass photosynthesis in root aerobic processes. Plant Physiology 74: 1055-1058.

Terrados, J., C. M. Duarte \& W. J. Kenworthy, 1997. Experimental evidence for apical dominance in the seagrass Cymodocea nodosa. Marine Ecology Progress Series 148: 263-268.

Terrados, J., C. M. Duarte, L. Kamp-Nielsen, N. S. R. Agawin, E. Gacia, D. Lacap, M. D. Fortes, J. Borum, M. Lubanski \& T. Greve, 1999. Are seagrass growth and survival constrained by the reducing conditions of the sediment? Aquatic Botany 65: 175-197.

Tomasko, D. A. \& C. J. Dawes, 1989. Evidence for physiological integration between shaded and unshaded short shoots of Thalassia testudinum. Marine Ecology Progress Series 54: 299-305.

Valiela, I., J. McClelland, J. Hauxwell, P. J. Behr, D. Hersh \& K. Foreman, 1997. Macroalgal blooms in shallow estuaries: controls and ecophysiological and ecosystem consequences. Limnology and Oceanography 42: 1105-1118.

Vichkovitten, T. \& M. Holmer, 2005. Dissolved and particulate organic matter in contrasting Zostera marina (eelgrass) sediments. Journal of Experimental Marine Biology and Ecology 316: 183-201.

Woolley, D. J. \& P. F. Wareing, 1972. The interaction between growth promoters in apical dominance. II. Environmental effects on endogenous cytokinin and gibberellin levels in Solanum andigena. New Phytologist 71: 1015-1025.

Zar, J. H., 1984. Biostatistical Analysis. Prentice-Hall, New Jersey.

Zimmerman, R. C., D. G. Kohrs \& R. S. Alberte, 1996. Topdown impact through a bottom-up mechanism: the effect of limpet grazing on growth, productivity and carbon allocation of Zostera marina L. (eelgrass). Oecologia 107: $560-567$. 